\title{
Introdução à nanotecnologia: Grafeno
}

\author{
Gonçalves, A.O.O. ${ }^{1}$; Zucolotto, C.G. ${ }^{2}$; Lana, J.M. ${ }^{3}$; Neves, R.P. ${ }^{4}$. \\ 1 Programa de Pós-Graduação em Engenharia Mecânica, Faculdade UCL, Serra, ES, Brasil
}

(O QUE COLOCAR AQUI)

\begin{abstract}
Resumo
Os estudos referentes ao carbono são de grande importância para a ciência e para a tecnologia, tendo em vista suas diversas aplicações. Este trabalho falará sobre a estrutura do elemento carbono, bem como seus tipos de hibridização e as diferentes geometrias geradas por elas. Além disso, tratará a respeito de seus alótropos mais comuns abordando seus comportamentos, propriedades e aplicações.
\end{abstract}

Keywords (Palavras chaves): Estrutura, Hibridização, Alótropos.

\section{Introdução}

O carbono é um elemento de grande importância, de forma que há um ramo da química que estuda seus compostos: a química orgânica. Suas características foram amplamente analisadas pelos cientistas Archibald Scott Couper e Friedrich August Kekulé, que no século XIX deram origem aos postulados de Couper-Kekulé. Os postulados destacam três propriedades do carbono que explicam seu comportamento: a tetravalência constante do carbono, ou seja, sua capacidade de fazer até quatro ligações covalentes; a igualdade entre as quatro valências do carbono que, independente da posição do átomo ligado a ele, o composto orgânico será sempre o mesmo; e encadeamento ilimitado entre carbonos, podendo formar inúmeros compostos orgânicos diferentes.

A tetravalência do carbono é explicada pela teoria dos orbitais híbridos, isto é, a combinação entre um orbital do tipo $s$ e até três orbitais do tipo $p$. Existem três tipos de hibridização, a saber: $\mathrm{sp}^{3}, \mathrm{sp}^{2}$ e $\mathrm{sp}$. A hibridização do tipo $\mathrm{sp}^{3}$ combina um orbital do tipo $s$ com três orbitais $\mathrm{p}$, gerando quatro orbitais atômicos $\mathrm{sp}^{3}$, possibilitando quatro ligações sigmas e uma geometria tetraédrica. A hibridização do tipo $\mathrm{sp}^{2}$ combina um orbital s com dois $p$, gerando quatro orbitais atômicos do tipo $\mathrm{sp}^{2}$. Essa hibridização proporciona ao carbono uma geometria trigonal plana com três ligações do tipo sigma (mais forte) e uma do tipo pi (mais fraca). Já a hibridização do tipo sp forma uma geometria linear, uma vez que combina um orbital $s$ com um orbital $p$ para gerar dois orbitais híbridos do tipo sp. Dessa forma, o carbono pode ligar-se à outros átomos por meio de duas ligações sigma e duas ligações pi, simultaneamente.

De acordo com os inúmeros arranjos moleculares entre carbonos, substâncias simples diferentes são formadas. Essas substâncias diferentes são conhecidas como alótropos do carbono, em que cada uma apresenta uma geometria e configuração eletrônica que confere aos compostos propriedades espetaculares. Alguns dos principais alótropos são: diamante, grafite, fulereno, grafeno e nanotubo de carbono.

\section{Alótropos do carbono}

O diamante e a grafite foram as primeiras estruturas estáveis puramente de carbono a serem estudadas[1]. A grande diferença entre a grafite e o diamante é a estrutura que é definida na constituição deles: o diamante necessita de altas condições de pressão e temperatura; entretanto, para a grafite ser formada são necessárias condições de pressão e temperatura bem menores.

O diamante tem grande importância econômica, já que é utilizado como pedra preciosa após ser tratado e lapidado [2]. Além disso, é utilizado na industria como matéria-prima para brocas de perfuração e ferramentas de corte e polimento. Por ter hibridização $\mathrm{sp}^{3}, \quad$ o diamante apresenta apenas ligações do tipo sigma, que são ligações muito resistentes, e uma geometria tetraédrica (rede cristalina). Essas características o tornam um material rígido e estável. 
Já a grafite, apesar de mesma composição química que o diamante, apresenta uma estrutura mais frágil, que pode ser descrita como folhas de grafeno empilhadas umas sobre as outras. Apresenta hibridização $\mathrm{sp}^{2}$ e geomatria trigonal plana. Essa estrutura molecular proporciona características distintas ao material como maleabilidade (lápis de escrever), librificação, condução elétrica e térmica.

O fulereno é um conjunto de nano moléculas estáveis de carbono, como: C60; C70; C540 [3]. Essas nomenclaturas indicam a quantidade de carbono na estrutura que se organiza em hexágonos interligados por pentágonos, geometria conhecida como icosaedro truncado (bola de futebol). Estes componentes são sólidos de cor preta e, ao serem imersos em solução orgânica, como de benzeno, podem ser identificados, já que cada um apresenta uma cor característica [4]. Atualmente, por suas características fotofísicas e eletroquímicas, o fulereno é aplicado na bioquímica e na medicina como meio de transporte de substâncias, como por exemplo: quimioterápicos; antibióticos e antivirais em células; e agentes antioxidantes em cosméticos.

O grafeno tem estrutura de carbonos organizados em hexágonos formando uma folha, cuja espessura é de um átomo [5]. No grafeno os carbonos tem hibridização do tipo $\mathrm{sp}^{2}$, o que caracteriza ligações químicas entre os carbonos mais fortes no grafeno do que no diamante, que tem hibridização $\mathrm{sp}^{3}$. A ligação do tipo pi presente entre os átomos se "desloca", de forma que a condução de calor e eletricidade é facilitada no grafeno [6]. Essas características estruturais conferem ao grafeno maior capacidade de suportar tensão do que o diamante e de conduzir eletricidade e calor melhor que o silício, além de o tornar leve, flexível e transparente.

\section{Conclusões}

Este trabalho de revisão de literatura serve como base para o estudo do grafeno, um material à base de carbono com propriedades extremamente importantes. $\mathrm{O}$ entendimento deste material faz parte de um projeto de iniciação científica realizado na Faculdade UCL no qual tem-se como objetivo a proposta de aplicação da utilização de grafeno em processos importantes como o de purificação de água e ar.

\section{Agradecimentos}

Os autores agradecem a Faculdade UCL pelo apoio.

\section{Referências}

[1] Grafite e diamante são feitos do mesmo material, Porto Alegre. Disponível em $<$ http://www.universitario.com.br/ noticias/n.php?i=5384>. Acesso em: 02 Maio 2014.

[2] Sobre os alótropos de carbono, Brasília. Disponível em <http://nanohoje.blogspot.com.br/2011/04/carosnavegantes-hoje-vamos-conhecer.html>. Acesso em: 02 Maio 2014.

[3] Alótropos de carbono: diamante, grafite, fulerenos, negro de fumo, etc., Paraná. Disponível em: <http://educacao.uol.com.br/disciplinas/quimica/alotrop os-de-carbono-diamante-grafite-fulerenos-negro-defumo-etc.htm>. Acesso em: 02 Maio 2014.

[4] Fulerenos - da promessa à realidade, Santa Catarina. Disponível em $<$ http://hypescience.com/fulerenos-da-promessa-arealidade>. Acesso em: 03 Maio 2014.

[5] O teórico do grafeno, Portugal. Disponível em $<$ http://www.superinteressante.pt/index.php?option= com_content\&view=article\&id=1355:o-teorico-dografeno\&catid=15:artigos\&ltemid=92>. Acesso em: 04 Maio 2014.

[6] Grafeno - o mateiral mais fino do mundo: um átomo de espessura, Portugal. Disponível em <http://efisica.fc.up.pt/fisica_na_up/conteudos/grafeno>. Acesso em: 04 Maio 2014.

[7] Grafeno - características, Rio de Janeiro. Disponível em: <http://www.pontoxp.com/grafeno-caracteristicas/>. Acesso em: 04 Maio 2014. 